\title{
Dissimilar Metal Joining of Aluminum and Copper Plates Using Magnetic Pulse Welding and Their Joint Strength
}

\author{
Mitsuhiro Watanabe ${ }^{1}$, Shinji Kumai ${ }^{2}$ \\ ${ }^{1}$ Department of Precision Machinery Engineering, College of Science and Technology, Nihon University \\ 7-24-1 Narashinodai, Funabashi-shi, Chiba 274-8501, Japan \\ watanabe.mitsuhiro@nihon-u.ac.jp \\ ${ }^{2}$ Department of Materials Science and Engineering, School of Materials and Chemical Technology \\ Tokyo Institute of Technology, 2-12-1 O-okayama, Meguro-ku, Tokyo 152-8552, Japan \\ kumai.s.aa@m.titech.ac.jp
}

\begin{abstract}
Lap joining of aluminum and copper was performed using magnetic pulse welding. Two kinds of joining methods were examined. One method is joining using aluminum as the flyer plate ( $\mathrm{Al} / \mathrm{Cu}$ joining). The other method is joining using copper as the flyer plate $(\mathrm{Cu} / \mathrm{Al}$ joining). The joining of aluminum and copper using the two methods at a charging energies from $0.5 \mathrm{~kJ}$ to $7.0 \mathrm{~kJ}$ was performed, and joint strength and interfacial microstructure were compared. The joint strength was evaluated by using tensile shear test. Interfacial microstructure was examined by using an optical microscope and a scanning electron microscope. $\mathrm{Al} / \mathrm{Cu}$ joining succeeded at charging energy higher than $1.5 \mathrm{~kJ}$. In contrast to that, $\mathrm{Cu} / \mathrm{Al}$ joining was achieved at charging energy higher than $5.0 \mathrm{~kJ}$. This different weldable charging energy range is considered to be due to density difference of aluminum and copper. In both joints, the fracture occurred at aluminum base metal by tensile shear test but the fracture strength of the $\mathrm{Cu} / \mathrm{Al}$ joints was lower than that of $\mathrm{Al} / \mathrm{Cu}$ joints. In case of $\mathrm{Cu} / \mathrm{Al}$ joining, copper used as the flyer plate compressed aluminum as the parent plate, and obvious thickness decrease of aluminum was observed. The thickness decrease of aluminum is considered to result in the lower fracture strength of $\mathrm{Cu} / \mathrm{Al}$ joints. Welding interface exhibited characteristic wavy morphology, which is similar to explosively welded interface. Intermediate layer was produced along the wavy interface. The wavy morphology and amount of intermediate layer of $\mathrm{Cu} / \mathrm{Al}$ joints were smaller than that of $\mathrm{Al} / \mathrm{Cu}$ joints.
\end{abstract}

Keywords: Magnetic Pulse Welding, Aluminum, Copper, Joint Strength, Microstructure.

\section{Introduction}

Joining of dissimilar metals is a kind of important technique for high-functionalization and multi-functionalization of machine. Formation of thick brittle intermetallic compound (IMC) layers is known to inhibit the fabrication of dissimilar metal joint with high-strength welding interface. The brittle IMC layers are usually formed in fusion welded joints and diffusion bonded joints [1]. These results mean that the brittle IMC layers are formed by the excess heat input to the welding interface and the long-time exposure at a high temperature. Therefore, short time welding method with minimum heat input to the welding interface is expected for fabricating of sound dissimilar metal joints.

Solid-state welding is attractive attention for dissimilar metal joining, because the inputted heat is smaller than that of fusion welding. Magnetic pulse welding is a kind of solid-state welding, and one metal plate is deformed by electromagnetic force and welding is achieved by high-speed oblique collision of two plates [2]. A time required for the welding process is usually within 10 microseconds. No heat is felt from the joints just after this welding process. This indicates that magnetic pulse welding is one of solution for fabricating of sound dissimilar metal joints. Actually, several combination of dissimilar metal joints with high strength have been fabricated by magnetic pulse welding [3]. However, in this method, one metal plate (hereafter flyer plate) is limited to a metal having high electrical conductivity, because eddy current need to be generated at surface of the flyer plate for inducing electromagnetic force. In case of joining of $\mathrm{Al}$ and $\mathrm{Cu}$, both metals can be used as the flyer plate. However, since properties of $\mathrm{Al}$ and $\mathrm{Cu}$ are different, properties of joints, especially joint strength and interfacial microstructure, may be different. In this study, magnetic pulse welding of $\mathrm{Al}$ and $\mathrm{Cu}$ was performed using $\mathrm{Al}$ or $\mathrm{Cu}$ as the flyer plate, and their joint strength and interfacial microstructure were compared. 


\section{Magnetic Pulse Welding}

Figure 1 shows schematic diagrams of principle of magnetic pulse welding. This method uses a discharge circuit composed of a capacitor, discharge gap switch and coil for generating electromagnetic force, as shown in Fig. 1(a). Two metal plates stacked with a small gap are fixed on the coil. Here, the metal plate set at the coil side is called "flyer plate" and the other metal plate is called "parent plate". When the capacitor is stored an electrical energy and then the discharge gap switch is closed, a discharge pulse passes through the coil. A high-density magnetic flux is generated around the coil. Eddy currents are induced at the surface of the flyer plate by crossing of the magnetic flux lines and the flyer plate surface. Electromagnetic force is generated by interaction between the eddy current and the magnetic flux (Fig. 1(b)). The flyer plate is deformed with a high speed toward the parent plate by the electromagnetic force, and the deformed flyer plate collides with the parent plate and joining of the two plates is performed. The joining is usually achieved within 10 microseconds. A metal plate with high electrical conductivity is suitable for the flyer plate.

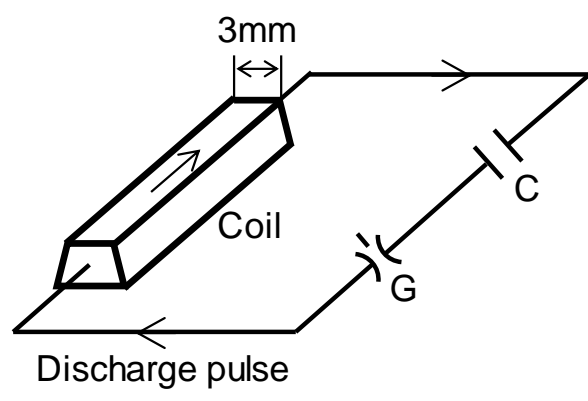

(a)

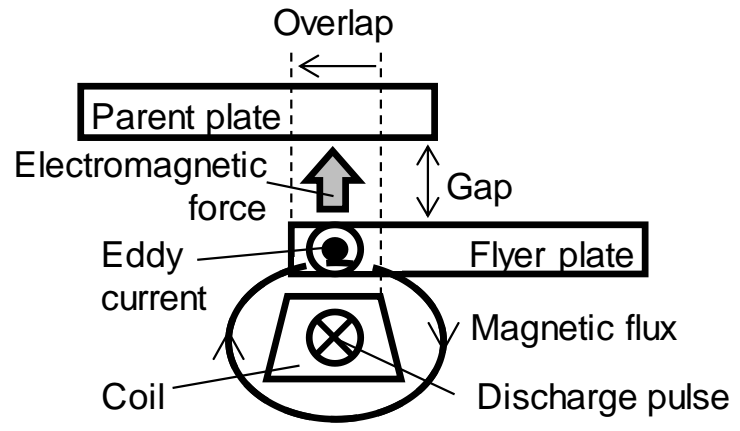

(b)

Fig. 1: (a) Discharge circuit. (b) Principle of magnetic pulse welding.

\section{Experimental Procedure}

$0.5 \mathrm{~mm}$ thick pure aluminum (A1050, hereafter $\mathrm{Al})$ and pure copper plates $(\mathrm{C} 1100$, hereafter $\mathrm{Cu})$ were prepared. The plate surfaces were cleaned by acetone in an ultrasonic cleaner and were dried well in air before the welding is performed.

The joining of $\mathrm{Al}$ and $\mathrm{Cu}$ was performed using a magnetic pulse system (Bmax, MP 12.5/25). The flyer plate was overlapped the coil for $3 \mathrm{~mm}$ and the parent plate was set above the flyer plate with a gap of $1.0 \mathrm{~mm}$. The energy charged in the capacitor before the welding (charging energy) was changed from $0.5 \mathrm{~kJ}$ to $7.0 \mathrm{~kJ}$. Hereafter, joining of $\mathrm{Al}$ and $\mathrm{Cu}$ using $\mathrm{Al}$ as the flyer plate is called " $\mathrm{Al} / \mathrm{Cu}$ joining" and joining of $\mathrm{Al}$ and $\mathrm{Cu}$ using $\mathrm{Cu}$ as the flyer plate is called " $\mathrm{Cu} / \mathrm{Al}$ joining".

Joint strength was evaluated by using tensile shear test. Shape of the specimens followed the Japanese Industrial Standard 13B. The weld part was located at the central position of the gage part. The tensile shear test was performed using an Instron type tensile tester with tensile speed of $1.0 \mathrm{~mm} / \mathrm{min}$ at room temperature.

Interfacial microstructure was examined using an optical microscope and a scanning electron microscope (SEM). SEM observation was carried out at acceleration voltage of $15 \mathrm{kV}$. The samples for microstructural observation were cut perpendicular to the seam direction of the lap joints and the cross section was polished.

\section{Results and Discussion}

\subsection{Effect of Flyer Plate Metal on Welding Feasibility and Joint Strength}

In order to investigate effect of flyer plate metal on welding feasibility, the charging energy for $\mathrm{Al} / \mathrm{Cu}$ joining and $\mathrm{Cu} / \mathrm{Al}$ joining was varied from $0.5 \mathrm{~kJ}$ to $7.0 \mathrm{~kJ}$. When $\mathrm{Al} / \mathrm{Cu}$ joining was performed using $\mathrm{Al}$ plate as the flyer plate, $\mathrm{Al} / \mathrm{Cu}$ joining was achieved at the charging energy over $1.5 \mathrm{~kJ}$. In contrast to that, when $\mathrm{Cu} / \mathrm{Al}$ joining was carried out using $\mathrm{Cu}$ plate as the flyer plate, $\mathrm{Cu}$ was welded to $\mathrm{Al}$ at the charging energy over $5.0 \mathrm{~kJ}$. This indicates that the welding feasibility is influenced by flyer plate metal even if the welding combination is the same. It was found that when $\mathrm{Cu}$ is used as the flyer plate, approximately 3.3 times more energy is required than using $\mathrm{Al}$ as the flyer plate.

In magnetic pulse welding, a part of a flyer plate, which is on the coil, deforms at a high speed toward a parent plate, and the joining is achieved by high-speed oblique collision between the deformed flyer plate and the parent plate. The welding 
feasibility depends on collision velocity and angle during the oblique collision and the weldable condition range is different depending on the welding combination. In case of the present study, the weldable condition should be same even when the flyer plate metal is changed, because the welding combination is same. However, the range of the weldable charging energy was different for $\mathrm{Al} / \mathrm{Cu}$ joining and $\mathrm{Cu} / \mathrm{Al}$ joining. This is assumed to be due to different kinetic energy of the flyer plate. The kinetic energy of the flyer plate is directly proportional to the mass of the deformed part and to the square of the collision velocity. The deformed part is same even when the flyer plate metal is changed. However, the density of $\mathrm{Cu}\left(8.9 \mathrm{Mg} / \mathrm{m}^{3}\right)$ is approximately 3.3 times larger than that of $\mathrm{Al}\left(2.7 \mathrm{Mg} / \mathrm{m}^{3}\right)$. Therefore, it is considered that $\mathrm{Cu} / \mathrm{Al}$ joining was achieved at a charging energy of $5.0 \mathrm{~kJ}$ which is approximately 3.3 times higher than $1.5 \mathrm{~kJ}$ of minimum charging energy capable of $\mathrm{Al} / \mathrm{Cu}$ joining.

Figure 2 shows relationship between fracture load measured by the tensile shear test of the joints and charging energy stored in the capacitor for joining. In the $\mathrm{Al} / \mathrm{Cu}$ joints fabricated at charging energy higher than $2.0 \mathrm{~kJ}$, the fracture load corresponded to that of the original Al (approximately $750 \mathrm{~N}$ ) and the fracture occurred in $\mathrm{Al}$ (Fig. 3(a)). In the $\mathrm{Cu} / \mathrm{Al}$ joints fabricated at charging energy higher than $6.0 \mathrm{~kJ}$, the fracture occurred in $\mathrm{Al}$ (Fig. 3(b)) but the fracture load was lower than that of the original Al. In order to investigate the reason, cross section of the joints was observed (Fig. 4). In the $\mathrm{Cu} / \mathrm{Al}$ joint, $\mathrm{Cu}$ used as the flyer plate compressed $\mathrm{Al}$ used as the parent plate and obvious thickness decrease of Al was observed, whereas thickness of $\mathrm{Cu}$ used as the parent plate is same to that of the original $\mathrm{Cu}$ in $\mathrm{Al} / \mathrm{Cu}$ joint. The lower fracture strength of $\mathrm{Cu} / \mathrm{Al}$ joints is considered to be due to the thickness decrease of Al.

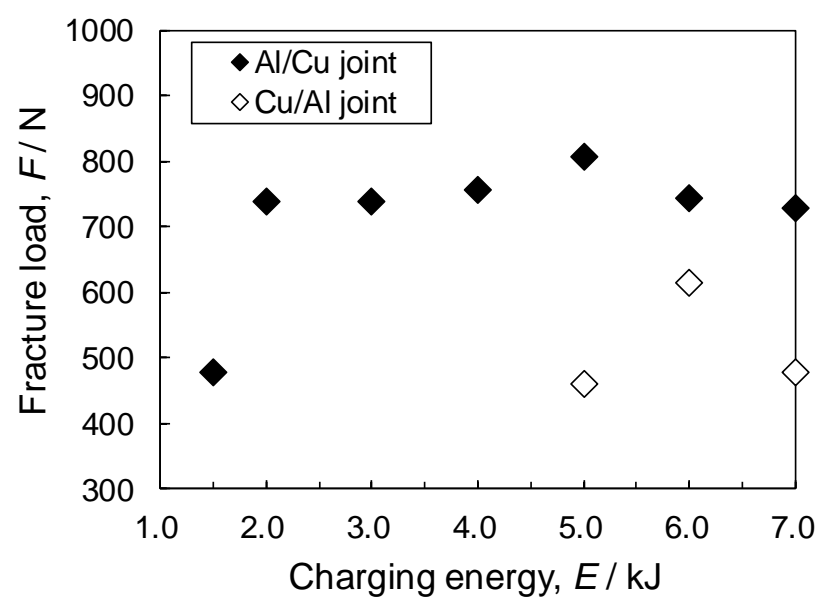

Fig. 2: Relationship between fracture load and charging energy.
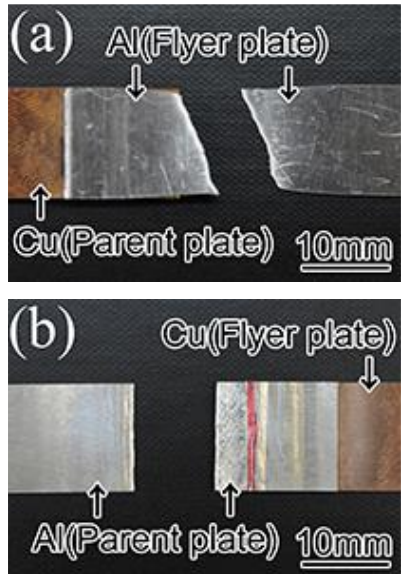

Fig. 3: Appearances of (a) $\mathrm{Al} / \mathrm{Cu}$ and (b) $\mathrm{Cu} / \mathrm{Al}$ joints after tensile shear test. 


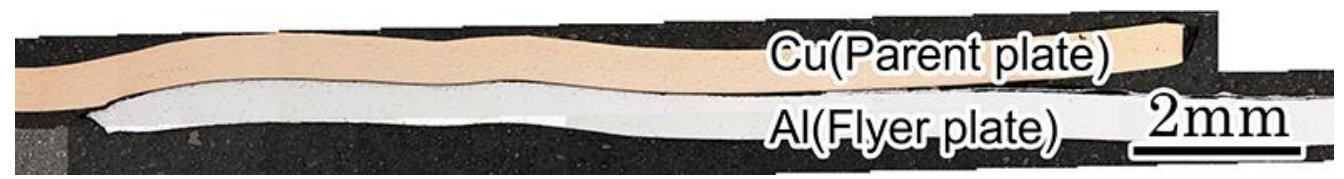

(a)

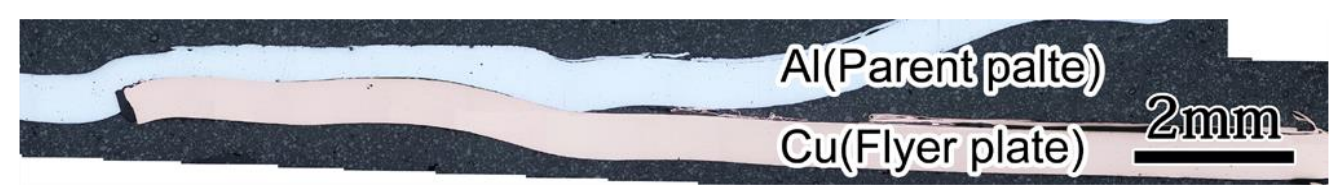

(b)

Fig. 4: Optical micrographs of cross sections of (a) $\mathrm{Al} / \mathrm{Cu}$ and (b) $\mathrm{Cu} / \mathrm{Al}$ joints.

\subsection{Interfacial Microstructure of $\mathrm{Al} / \mathrm{Cu}$ and $\mathrm{Cu} / \mathrm{Al}$ Joints}

Figure 5 shows SEM-backscattered images of the welding interface of (a) $\mathrm{Al} / \mathrm{Cu}$ and (b) $\mathrm{Cu} / \mathrm{Al}$ joints. The upper side is the parent plate metal and the lower side is the flyer plate metal. The welding interface exhibited characteristic wavy morphology in both $\mathrm{Al} / \mathrm{Cu}$ and $\mathrm{Cu} / \mathrm{Al}$ joints. The wavy welding interface has been observed in the joints fabricated by using explosively welding and water jet welding. In these welding methods, it is common to weld two metal plates by high-speed oblique collision. Therefore, high-speed oblique collision between the flyer plate and the parent plate is considered to occur during magnetic pulse welding process. The intermediate layer was produced along the wavy interface. The wavy morphology and amount of the intermediate layer in the $\mathrm{Cu} / \mathrm{Al}$ joint were smaller than that of the $\mathrm{Al} / \mathrm{Cu}$ joint. Since joining combination is similar between the $\mathrm{Al} / \mathrm{Cu}$ and the $\mathrm{Cu} / \mathrm{Al}$ joining, if similar collision bahavior is demonstrated, similar welding interface should be obtained. As mentioned above, in case of the $\mathrm{Cu} / \mathrm{Al}$ joining, $\mathrm{Cu}$ used as the flyer plate compressed $\mathrm{Al}$ used as the parent plate (Fig. 4(b)). Therefore, it is assumed that different collision behavior occurred during the $\mathrm{Al} / \mathrm{Cu}$ joining and $\mathrm{Cu} / \mathrm{Al}$ joining.

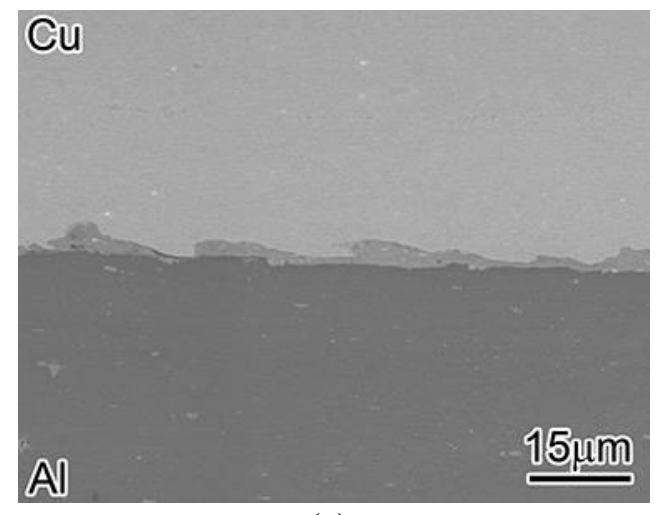

(a)

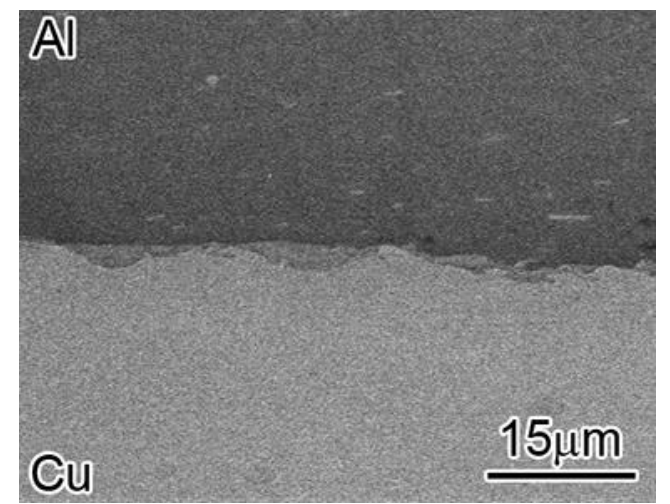

(b)

Fig. 5: SEM-backscattered electron images of welding interface in (a) $\mathrm{Al} / \mathrm{Cu}$ and (b) $\mathrm{Cu} / \mathrm{Al}$ joints.

\section{Conclusions}

Magnetic pulse welding of aluminum and copper was achieved using aluminum or copper as the flyer plate. When aluminum was used as the flyer plate, the joining succeeded at charging energy higher than $1.5 \mathrm{~kJ}$. When copper was used as the flyer plate, the joining was achieved at charging energy higher than $5.0 \mathrm{~kJ}$. This different weldable charging energy range is considered to be due to density difference of aluminum and copper. Formations of wavy welding interface and intermediate layer produced along the welding interface were observed in both joints. The wavy morphology and amount of intermediate layer in the $\mathrm{Cu} / \mathrm{Al}$ joint were smaller than that of the $\mathrm{Al} / \mathrm{Cu}$ joint.

\section{Acknowledgement}

A part of this study was financially supported by a grant-in-aid of research from Amano Institute of Technology. 


\section{References}

[1] M. J. Torkamany, S. Tahamtan and J. Sabbaghzadeh, "Dissimilar welding of carbon steel to 5754 aluminum alloy by Nd:YAG laser," Mater. Des., vol. 31, no. 1, pp. 458-465, 2010.

[2] M. Watanabe and S. Kumai, "High-speed Deformation and Collision Behavior of Pure Aluminum Plates in Magnetic Pulse Welding," vol. 50, no. 8, pp. 2035-2042, 2009.

[3] S. Kumai, M. Watanabe and K. Feng, "Microstructure and Joint Strength of Similar- and Dissimilar Lap Joints Fabricated by Several Advanced Solid-State Welding Methods," Mater. Sci. Forum, vol. 654-656, pp. 596-601, 2010. 